\title{
Definite descriptions and negative existential quantifiers
}

\author{
Paul Elbourne ${ }^{1}$
}

Published online: 27 May 2017

(c) The Author(s) 2017. This article is an open access publication

\begin{abstract}
Previous theorists have claimed that Russell's theory of definite descriptions gives the wrong truth conditions to sentences in which definite descriptions are embedded under certain other operators; but the other operators used, such as conditionals and propositional attitude verbs, have introduced intensional and hyperintensional complications that might be thought to obscure the point against Russell. This paper shows that the same kind of problem arises when the operator in question (English 'no') allows the context to be extensional. It is further argued that presuppositional theories of definite descriptions give intuitively satisfying analyses of the novel data.
\end{abstract}

Keywords Definite descriptions · Presupposition · Generalized quantifiers

\section{Introduction}

The purpose of this paper is to explore a novel variant of a certain type of objection to Russell's theory of definite descriptions (Russell 1905) (henceforth 'the Russellian theory'). Briefly, it will argue that sentences involving definite descriptions embedded under negative existential quantifiers like 'no' are given the wrong truth conditions by the Russellian theory.

As is well known, the Russellian theory claims that sentences of the form (1a) have truth conditions that can be described as in (1b), (1c), or (1d). ${ }^{1}$

\footnotetext{
${ }^{1}$ It need scarcely be added that the Russellian theory still commands the loyalty of a significant number of philosophers. It has been defended in print in recent years by Neale $(2004,2005,2007)$, Bach

Paul Elbourne

paul.elbourne@magd.ox.ac.uk

1 Magdalen College, Oxford OX1 4AU, UK
} 
(1) a. The $\mathrm{F}$ is $\mathrm{G}$.

b. There is exactly one $\mathrm{F}$ and it is $\mathrm{G}$.

c. There is an entity such that it is $\mathrm{F}$ and nothing else is $\mathrm{F}$ and it is $\mathrm{G}$.

d. $\exists x(F x \& \forall y(F y \supset y=x) \& G x)$

The Russellian theory is arguably open to several types of objection (Elbourne 2013: 231). One of these objections targets the readings available for sentences in which definite descriptions are embedded below other operators in the syntax (henceforth 'embedded cases'). It is sometimes found, in embedded cases, that the readings available do not tally with those predicted by a straightforward application of the theory. The embedded cases most often discussed have involved conditionals and propositional attitude reports (Heim 1991; Elbourne 2005, 2010, 2013; Neale 2005; Rothschild 2007; Hawthorne and Manley 2012; Schoubye 2013). The strategy has generally been to compare sentences involving definite descriptions with sentences that are identical except that the truth-conditional contribution of the description is spelled out in explicitly Russellian terms. Example (3a), for example, does not, intuitively, have the same truth conditions as (3b):

(2) I do not know whether there is a ghost in Hans's attic.

(3) a. If the ghost in Hans's attic is quiet tonight, he will hold a party.

b. If there is exactly one ghost in Hans's attic and it is quiet tonight, Hans will hold a party.

Imagine that a speaker uttered (2) and then followed it up with (3a). Such a speaker would be felt to have contradictory beliefs (or else an imperfect grasp of English). But no such charge would be levelled at a speaker who said (2) and followed it with (3b). So (3a) and (3b) do not have the same truth conditions. But (3b) is just (3a) with the definite description spelled out in accordance with the Russellian theory. So the Russellian theory is not accurate. Or so the objection goes.

Similarly, a speaker who said (2) and followed it up with (4a) would sound selfcontradictory. One who followed (2) with (4b), however, would not.

(4) a. I am wondering whether the ghost in Hans's attic is being noisy.

b. I am wondering whether there is an entity such that it is a ghost in Hans's attic and nothing else is a ghost in Hans's attic and it is being noisy.

Variants of this objection have also been run using questions and imperatives (Searle 1969; Rothschild 2007) and possibility modals (Rothschild 2007; Elbourne 2013). Someone asking (5a), for example, is not, intuitively, allowing the number of the addressee's wives to be subject to question, as would appear to be the case if (5a) had a meaning similar to that of (5b).

Footnote 1 continued

(2007a, b), Pupa (2010, 2013), Abrusán and Szendrői (2013), and Jandrić (2014), among others. One also hears defences of it in conversation and in seminars, often by people who are worried about giving up bivalence. This latter move is often taken to be a necessary consequence of adopting a presuppositional approach to definite descriptions. But see footnote 13 . 
(5) a. Is your wife here?

b. Is it the case that you have exactly one wife and she is here?

And someone who says (2) and follows it up with (6a) sounds just as confused as someone who follows it up with (3a) or (4a). But this would not be so if (6a) had the truth conditions in (6b), which are those predicted by the Russellian theory.

(6) a. It is possible that the ghost in Hans's attic will be quiet tonight.

b. It is possible that there is exactly one ghost in Hans's attic and it will be quiet tonight.

Thus, in brief summary, the criticism of the Russellian theory that has been made on the basis of embedded cases.

In my opinion, embedded cases present a serious difficulty for the Russellian theory. But I maintain that there are two gaps that should be filled in order to make the case even more formidable than it already is. The first gap involves the possible muddying effect of the contexts involved in the examples used so far. It is notable that the embedded cases previously discussed in the literature all involve sentences that are theoretically challenging in other ways too: the relevant contexts are all (arguably) intensional, hyperintensional, or non-assertoric. Now since the same kind of difficulty seems to arise for the Russellian theory across all the different contexts mentioned above, it is extremely likely, in my view, that the cause is a fault in the Russellian theory. But the theoretically challenging nature of the contexts involved might possibly be thought to enable the friend of the Russellian theory to claim the opposite. The idea would be that the behaviour of definite descriptions in embedded cases has more to do with the peculiarities of those contexts than with any deficiencies there might be in the Russellian theory. A restricted version of this option has already been taken up, in fact, by Kaplan (2005: 985) and Neale (2005: 846), who argued that embedded cases involving propositional attitude reports can be explained on the basis of a peculiarity of propositional attitude contexts, namely that they are not closed under entailment. Now this particular avenue of investigation arguably did not explain even the propositional attitude examples (Elbourne 2010, 2013; Hawthorne and Manley 2012; Schoubye 2013); and it is notable that the relevant contexts in some other embedded cases, such as those involving possibility modals, are, in fact, closed under entailment. But still it is, I think, worth allaying this general kind of suspicion by presenting an embedded case which is unimpeachably extensional and assertoric. That is the primary thing that I do in this paper (Sect. 2).

The second gap that should ideally be filled concerns a recent defence of the Russellian theory's capabilities in this area by Pupa (2013). In Sect. 3.4, after some other rival explanations of the data in Sect. 2 have been dismissed, this defence is explained and prospects for extending it to cover the data in Sect. 2 are explored. It is then subjected to independent criticism.

The paper then argues (Sect. 4) that presuppositional theories of definite descriptions can give adequate accounts of the novel data. Section 5 concludes. 


\section{The central example}

Consider the following example, in which a definite description is embedded under the generalized quantifier 'no boy':

(7) No boy sold the dog he had bought.

The following facts about this example are intuitively clear and will be used to judge theories about it now and later on:

(8) a. Fact A: (7) is not true in any scenario in which no boy bought any dog.

b. Fact B: (7) is not true in any scenario in which all the boys bought two or more dogs.

The Russellian theory predicts (7) to have the following reading, assuming that 'he' is bound by 'no boy' and using the obvious dictionary:

(9) $\sim \exists x(B x \& \exists y((D y \& B x y) \& \forall z((D z \& B x z) \supset z=y) \& S x y))$

This is equivalent to the following:

(10) No boy bought exactly one dog and sold it.

It is clear, however, that (7) is truth-conditionally distinct from (10). For one thing, (10) is true in a scenario in which no boy bought any dog; (7) is not (Fact A). Likewise, (10) is true in any scenario in which all the boys being quantified over bought two or more dogs; (7), however, is not (Fact B). (There do not seem to be any scenarios in which (7) is true and (10) is not; (7) entails (10) in other words, although the converse does not hold.) So the Russellian theory has encountered another problem arising from an embedded case. And this time, in contrast to the previous embedded cases discussed, the context is straightforwardly extensional and assertoric.

\section{Some possible counterarguments}

I will consider four possible defences that a friend of the Russellian theory might mount on its behalf.

\subsection{Pragmatic oddity}

First, one might be tempted to analyse the data by claiming that the Russellian truthconditional meaning of (7), as represented in (9), is pragmatically odd or difficult to process. But the equivalence of (9) and (10) rules this out. The truth conditions of (9) are just the truth conditions of (10); and (10) is entirely felicitous even out of the blue. It would be a perfectly sensible thing to say under some circumstances. It is just not equivalent to (7). 


\subsection{Scope}

Secondly, it is tempting in some embedded cases to claim that the definite description must scope above the offending higher operator in the logical form of the sentence. This would arguably prevent the problematic truth conditions from emerging. Take (4a), for example, repeated here as (11a). If we could give the definite description obligatory wide scope, so that the truth conditions were those in (11b), we might be able to give an adequate account of this example using the Russellian theory: note that (11b) commits the speaker to the existence of a ghost in Hans's attic, unlike (4b) above; we would thus be able to explain why it sounds contradictory to say (11a) after (2).

(11) a. I am wondering whether the ghost in Hans's attic is being noisy.

b. There is exactly one ghost in Hans's attic and I am wondering whether it is being noisy.

This strategy is rather stipulative and is subject to other difficulties discussed in the previous literature (Elbourne 2013: 153-4, 156). But in any case it cannot be an appropriate analysis here: in the reading of (7) that concerns us, 'no boy' binds, and so must have scope over, the pronoun 'he'; and 'he' appears in the descriptive material of the definite description; so 'no boy' has scope over the definite description. There is no doubt, then, that (9) is a logical form predicted for (7) by the Russellian theory.

\subsection{Comparison with indefinites}

Thirdly, one might argue against the force of (7) by using a tactic employed by Hawthorne and Manley (2012: 191) against some other embedded cases. In particular, these authors consider examples of the following kind (Elbourne 2005: 109):

(12) Hans wants the banshee in his attic to be quiet tonight.

The point of this example, of course, is that it does not seem to have the truth conditions of (13), which might seem to be predicted by the Russellian theory:

(13) Hans wants there to be exactly one banshee in his attic and for it to be quiet tonight.

As a possible defence of the Russellian theory at this point, Hawthorne \& Manley (2012: 191-2) point out that indefinites also do not seem to give rise to the truth conditions one would expect when placed in similar sentence frames:

(14) Hans wants a torturer to be executed.

This example does not mean the same as (15):

(15) Hans wants there to be a torturer and for him to be executed. 
The idea behind this comparison is that the existential quantificational force that is predicted for the definite description by the Russellian theory is not felt in (12): this example does not mean 'Hans wants there to be exactly one banshee in his attic...'. But Hawthorne and Manley (2012) point out that the existential quantificational force that we would expect from indefinites, according to the standard Russellian semantics accorded to them, also does not make itself felt in the context of 'Hans wants _ NP to VP'. The proposal, then, is that there is something about this sentence frame that has the effect of cancelling out existential force in determiners. Since we do not detect existential force in the case of (14), there is no reason why we should be expected to detect it in the case of (12), even if the Russellian theory is correct.

Now one might raise problems for this argument in this context, as has already been done by Elbourne (2013: 159-67) and Schoubye (2013). I will not recapitulate these earlier discussions here. In the current context, we will want to see if the analogous manipulation of the data produces an analogous effect. In particular, then, we should take (7) and substitute 'a' for 'the':

(16) No boy sold a dog he had bought.

And we should see if this sentence can be understood in such a way that the existential force of the indefinite article is clearly felt. If it cannot be so understood, an analogous argument to the one made by Hawthorne and Manley (2012) about propositional attitude contexts will be able to be launched. If it can be so understood, however, there will be no basis for any such argument.

Unfortunately for the prospects of this kind of argument, it is clear that (16) can be understood in such a way that the existential force of the indefinite article is clearly felt. That is, (16) can be understood to have the following truth conditions:

$$
\sim \exists x(B x \& \exists y((D y \& B x y) \& S x y))
$$

There is no basis in the current case, then, for an argument along the lines of the one explored by Hawthorne and Manley (2012) for propositional attitude contexts.

\subsection{Familiarity}

Pupa (2013) has proposed that we defend the Russellian theory against the problem of embedded cases by combining it with familiarity conditions for definite descriptions of the kind first proposed by Christophersen (1939).

Pupa (2013: 299) lays out the familiarity theory of definiteness as follows:

\footnotetext{
2 This is how some early versions of the problem of embedded cases were expressed (Heim 1991; Elbourne 2005). Following the observation by Kaplan (2005: 985) and Neale (2005: 846) that propositional attitude contexts were not closed under entailment, and so one would not necessarily expect to detect the existential entailment here, a different way of bringing out the problem was adopted by Elbourne (2010). It is this latter method that was followed in Sect. 1 of the current paper. I set things out in the older way now simply because I am following the train of thought of Hawthorne and Manley (2012).
} 
Familiarity theorists maintain that a definite description's felicitous use requires that the speaker believe that the audience is familiar with the individual satisfying the description's nominal; it requires that the speaker believe that the audience is familiar with the description's denotation.

Crucially, indefinite descriptions would not be associated with any such familiarity requirement. ${ }^{3}$

Pupa claims that we should see Russell's well known truth conditions for sentences involving definite descriptions as being just that: analyses of the truth conditions of such sentences. Russell, he says, was not in the business of providing felicity conditions; and so we need not see the Russellian theory and the familiarity theory as being in conflict (Pupa 2013: 301). His overall strategy, then, is to propose that sentences involving definite descriptions have the truth conditions proposed by Russell and also the familiarity conditions proposed by the familiarity theory. This, as he points out, might be thought to solve at least some of the difficulties raised for the Russellian theory by embedded cases. Take, for example, the contrast between (3a) and (3b), repeated here as (19a) and (19b), brought out by saying them after (2), repeated as (18).

(18) I do not know whether there is a ghost in Hans's attic.

(19) a. If the ghost in Hans's attic is quiet tonight, he will hold a party.

b. If there is exactly one ghost in Hans's attic and it is quiet tonight, Hans will hold a party.

Pupa (2013: 300-1) says that this contrast is to be expected according to his theory: given the familiarity conditions for felicitous use of definite descriptions, the use of a definite description in (19a) communicates that the audience is expected to be familiar with the denotation of the description (i.e. with the unique entity satisfying the content of the nominal). ${ }^{4}$ Infelicity will result if one says (19a) after (18), since

\footnotetext{
3 Pupa (2013: 299) says that 'an indefinite description's felicitous use is said to require that the speaker believe that the individuals the description denotes are novel to her audience.' This cannot be quite right, however, if by 'denotes' Pupa means 'applies to'; for it is surely possible to use the phrase 'a man' while being familiar with men. (And it is difficult to see what else 'denotes' could mean in this context; for, according to Russell, "there cannot be such an entity as "a man" to be found in the world, as opposed to specific men' (Russell 1919: 173); an indefinite description does not have a unique denotation in the way that a definite description does.) But possibly Pupa has in mind the more sophisticated familiarity theory of Heim (1982), in which only the relevant discourse referent has to be novel.

4 It is notable that Pupa does not lay out the familiarity theory of definiteness in quite the way that other familiarity theorists do. Instead of saying that the felicitous use of a definite description requires that the speaker believe that the denotation is familiar to the audience, as Pupa does, Roberts (2003), for example, says simply that felicitous use requires that the denotation be familiar to speaker and hearer. Pupa achieves the result that felicitous use requires that the denotation be familiar to the hearer by positing a pragmatic inference, as just described. And presumably the speaker will not believe that the hearer is familiar with the denotation (which is Pupa's condition) without being familiar with the denotation himor herself. It is likely enough that the two versions amount to same thing for current purposes that I will not spend time here trying to root out small differences between them. In particular, the two examples below that turn on the familiarity condition being violated, examples (23) and (24), both have the property that they are felicitous even though the hearer is not familiar with the denotation of the definite description concerned, which is clearly contrary to both versions of the familiarity theory of definiteness.
} 
with (18) the speaker appears to be expressing agnosticism as to the existence of the very denotation that the audience is expected to be familiar with in (19a). On the other hand, there is no definite description in (19b), so no comparable effect will be expected there. So we arguably arrive at a suitable contrast between (19a) and (19b) by means of Pupa's theory. Many other examples would work similarly.

So can this theory be applied to the new data put forward in the present article? It is not clear how it could be. Let us take example (7), repeated here as (20):

(20) No boy sold the dog he had bought.

Since the definite description in this example is bound into, it is not the case that it has a denotation, as defined above, since there is no one object that satisfies the description's nominal. So there is no object that would have to be familiar in this case, if we wished to analyse it by means of a familiarity theory. Pupa (2013) does not say how the notion of familiarity could be cashed out in a situation like this; nor do other prominent recent familiarity theorists (Heim 1982; Roberts 2003) provide explicit guidance.

Is there anything that can be done to rescue Pupa's theory at this point? Perhaps some way of generalizing it so that it covers the current case? The obvious expedient to try, I suppose, is to say that the definite description in (20), 'the dog he had bought', even though it has no denotation in absolute terms, does have one denotation with respect to each value of the pronoun 'he', given that 'he', as a bound pronoun, can be analysed as taking values that vary with the individuals quantified over by the higher quantifier phrase. If we interpret the definite description as successively taking on different semantic values, the ones respectively yielded up by the several values of the pronoun it contains, we might be thought to be able to arrive at a set of denotations for it. ${ }^{5}$ In this case, provided that each of the boys being quantified over did indeed buy exactly one dog, the set of denotations would presumably be the set of those dogs. Perhaps the relevant condition in cases like this might be that each member of the set thus arrived at has to be familiar to the hearer?

Unfortunately, this will not do. It is an essential characteristic of the Russellian theory that definite descriptions do not have to have denotations (Russell 1905: 488, 490-1). Some well known examples can be used to back up this assertion:

(21) The King of France is bald.

Since definite descriptions do not have to have denotations, we cannot rely on their having denotations for the purposes of applying the familiarity theory of definiteness in the way suggested by Pupa. This is particularly relevant in the case at hand, since the truth conditions of (20) are those in (10), repeated here as (22):

(22) No boy bought exactly one dog and sold it.

\footnotetext{
5 This would, of course, require us to follow neo-Russellians like Neale (1990) in viewing definite descriptions as having semantic values in the first place, as opposed to treating them in a syncategorematic fashion, as Russell (1905) himself did. But this should not present a problem.
} 
Since this is compatible with the boys not having bought any dogs, as pointed out above, we are not justified in positing denotations of any kind for the definite description in (20). But without denotations, the familiarity theory of definiteness is powerless to achieve anything, since denotations are the things that it claims are meant to be familiar. This is a quite general problem with the familiarity theory of definiteness and with Pupa's application of it.

Since Pupa's (2013) article is, as far as I know, the only recent defence of the Russellian theory against the problem of embedded cases, it is worth considering some other possible problems with it, not immediately connected with (20). I would claim that Pupa's theory, considered as a defence of the Russellian theory, is vulnerable to two additional kinds of criticism: first, it is not a Russellian theory at all but a hybrid theory, in which a familiarity-based theory is grafted onto the Russellian theory; second, the idea that the denotations of definite descriptions have to be familiar suffers from independent flaws that are not addressed in Pupa's paper (or anywhere else, as far as I am aware).

To expand on the first criticism, the traditional understanding of the Russellian theory has always been that declarative sentences containing definite descriptions have meanings (broadly construed) that involve the standard Russellian paraphrase and nothing else (or nothing else contributed in virtue of the fact that they contain definite descriptions, at least). Of course, the theory thus articulated is indeed incompatible with a theory that adds in familiarity conditions.

I do not intend to embark on an exhaustive survey of the literature on definite descriptions in order to demonstrate this point, which I take to be quite obvious to anyone who has read a substantial amount of this literature. But it might be of interest to review some relevant things that were written by Russell himself. In his original (1905) paper, Russell never talks of giving the 'truth conditions' of sentences containing 'the' (or anything equivalent to this). Instead he says that the task before him is to 'interpret' such sentences (1905: 481); and he talks about giving an 'interpretation' of them (1905: 482). He also uses the phrase 'what is meant' to describe one of his standard paraphrases (1905: 488); and he talks about what 'we normally mean' by such sentences (1905: 489). These phrases are sufficiently general that, if Russell did intend to be presenting a theory of only one aspect of the meaning of definite descriptions, he was writing in an extraordinarily misleading way. The impression that Russell assumed that there was nothing more to the semantics of definite descriptions than his standard paraphrase is strengthened when we read footnote 2 on page 481 of his classic paper. Here, Russell says 'Psychologically "C(a man)" has a suggestion of only one, and " $\mathrm{C}$ (some men)" has a suggestion of more than one; but we may neglect these suggestions in a preliminary sketch.' He provides no such 'psychological suggestions' in the case of 'the', however, making it natural to suppose that he did not detect any and did not wish to suggest that any be incorporated into a more detailed theory.

As far as I can see, however, we have to wait for Russell's Introduction to Mathematical Philosophy (1919) for an explicit indication of Russell's thoughts on this matter. On page 176 of that work, after a presentation of the Russellian theory of indefinite descriptions, we read the following: 
We are now in a position to define propositions in which a definite description occurs. The only thing that distinguishes 'the so-and-so' from 'a so-and-so' is the implication of uniqueness.

The second sentence here rules out the possibility that Russell would allow that 'the so-and-so' and 'a so-and-so' might also differ in familiarity conditions, as claimed by Pupa (2013). Russell would presumably not have written this sentence if he had seen himself as giving a theory of only one aspect of the meanings of definite and indefinite descriptions. 6,7

We must conclude that Pupa's attempt to defend the Russellian theory by adding familiarity conditions to it is not really a defence of the Russellian theory at all. It is the invention of a new, hybrid, theory and a renunciation of the Russellian theory. ${ }^{8}$

The second possible criticism of Pupa's theory is that the requirement that the denotations of definite descriptions be familiar suffers from independent flaws. ${ }^{9}$ Consider the following example (Hawkins 1978: 131):

A: What's wrong with Bill?

B: Oh, the woman he went out with last night was nasty to him.

It would be entirely possible for B's utterance to take place in a context in which it is not part of the common ground that Bill went out with a woman the previous night. Nor need the woman in question be familiar for any other reason. But B's utterance is entirely felicitous in such a context. This is mysterious if, as Pupa says, the use of a definite description communicates that the audience is expected to be familiar with its denotation. But a theory that explains the semantics of definite descriptions in terms of uniqueness, without bringing in familiarity, is well placed to explain this. The Russellian theory will just say that B asserts that there is exactly one woman that Bill went out with on the night in question and that she was nasty to him. A Fregean theory, in which (roughly speaking) definite descriptions are referential and existence and uniqueness with respect to the nominal content are presupposed (Frege 1892; Heim 1991; von Fintel 2004; Elbourne 2005, 2013; Rothschild 2007), will say that the audience has to accommodate the presupposition that there is exactly one woman that Bill went out with the previous night. If the

\footnotetext{
${ }^{6}$ It might be alleged that the talk of 'propositions' here means that the scope of this remark is restricted to the truth-conditional aspect of meaning. But this is not the case. As the phrase 'in which a definite description occurs' indicates, given that definite descriptions are linguistic objects, 'proposition' here is being used to mean something like declarative sentence. Russell frequently slips back and forth between using 'proposition' in this linguistic sense and using it as we would today, as Salmon (2004: 237) and Soames (2014: 332) have already noted.

7 Given the copious natural language data that we meet with in Russell 1905 and other linguistically oriented works by Russell, I take it as evident that Russell was actually interested in analysing natural language, despite the claims one occasionally hears to the contrary. See Green 2007 for a good discussion of this whole area. Of course neo-Russellians like Neale (1990) make clear their interest in applying the Russellian theory to natural language.

8 The reader might like to consult Schoubye 2013 for further discussion and dismissal of hybrid Russellian theories of this kind.

9 The following summary of the problems here is based closely on that given by Hawthorne and Manley (2012: 164-5).
} 
person who introduced the presupposition is deemed reliable, there will be no problem with this.

Pupa (2013: 304) suggests that at least some cases of this kind can be dealt with by accommodation:

In many cases, when a speaker makes an unfamiliar use of a definite description, her audience will, for conversation's sake, assume that the denotation is indeed familiar just so long as the assumption is uncontroversial.

But note the difference between this kind of accommodation and the kind required in this case by presuppositional theories of definite descriptions. Presuppositional theories will say, about this case and many others, that speakers have to accommodate something that is, as far as they know, true: the fact that Bill went out with a woman on the night in question, in this case. But familiarity theories have to say that speakers have to accommodate something which they know to be false, namely that the woman in question was already familiar. By stipulation, in this example, this woman was not familiar; nor, in case it matters, was it already part of the common ground that Bill went out with a woman on the night in question. It is puzzling why an utterance should be completely felicitous when it forces the audience to accommodate something that they know to be false. As Hawthorne and Manley (2012: 165) say about a variant of the current example, we would expect at least an inkling of this peculiar demand in the phenomenology of the exchange. But there is nothing.

Pupa (2013: 305) acknowledges that a case very similar to (23) is probably not a good candidate for accommodation. His proposal for such cases is that the speech acts in question 'seem defective in retrospect'. But they do not. Neither Hawkins (1978: 101) nor Hawthorne and Manley (2012: 164-5), who discuss cases like (23), detect the slightest hint of conversational impropriety in these examples; nor does Roberts (2003: 302), an advocate of a version of the familiarity theory. ${ }^{10}$

The only other consideration offered by Pupa (2013: 304) is to suggest that '[f]elicity conditions are not iron laws, but rough and ready rules. It's not unexpected that occasional violations bubble up here and there.' But in the absence of a clear theory of the conditions under which such violations make their appearance, we have not really been given anything to work with here.

We have not even considered, as yet, the most difficult examples for the familiarity theory of definiteness. These examples are ones in which familiarity of the denotation of the definite description is explicitly denied in the examples themselves and yet the examples are still felicitous. Here is an example devised by Hawthorne and Manley (2012: 165), based closely on one by Abbott (2008: 64):

(24) Since you don't know much about MSU, I'm sure you haven't heard of the new curling centre there.

It is difficult to see how any kind of accommodation mechanism could get off the ground here. How can the hearer accommodate the familiarity of the new curling

${ }^{10}$ Roberts (2003: 302-3) advocates the use of accommodation for these cases, as criticized above. 
centre when it is not only not familiar but also explicitly stated to be unfamiliar by the speaker? But accommodation is the only mechanism that has been suggested on behalf of the familiarity theory to get around the numerous cases in which the denotations of definite descriptions are just not familiar.

I maintain, then, that we should not adopt Pupa's (2013) suggestion of salvaging the Russellian theory by adding familiarity conditions to it.

\section{Presuppositional theories}

Before we leave our topic, I would like to argue that presuppositional theories of definite descriptions can deal well with the data at hand. (This follows analogous claims for other embedded cases in the previous literature (Heim 1991; Elbourne 2010, 2013).)

Probably the best known presuppositional theory of definite descriptions claims that they are basically referential and that a definite description 'the F' introduces a presupposition to the effect that there is exactly one F, perhaps in a particular salient domain or situation (Frege 1892; Heim 1991; von Fintel 2004; Elbourne 2005, 2013; Rothschild 2007; Schoubye 2013); if the presupposition is satisfied, the definite description 'the F' refers to the unique F. Call such theories Fregean presuppositional theories. On the other hand, it has also been claimed that a presupposition to the effect that there is exactly one F is combined, in the semantics of definite descriptions, with an assertion to the effect that there is exactly one F or with an assertion to the effect that there is at least one F (Karttunen and Peters 1979; Abbott 2008; Hawthorne and Manley 2012). Let us call theories of this type quantificational presuppositional theories. The question now is what predictions Fregean and quantificational presuppositional theories make about the data in this paper. Let us concentrate on (7) ('No boy sold the dog he had bought'), our original example.

Among theorists who believe that definite descriptions are presuppositional, there are two schools when it comes to the theory and empirical investigation of the presuppositions of sentences like (7) (that is, of sentences in which the nuclear scope of a quantifier triggers a presupposition and contains a bound variable). In setting out the views of these schools, it will be convenient to adopt some semiformal notation sometimes used by the authors in question. We are dealing with a sentence with the following semantics:

$$
\llbracket \text { no } \rrbracket(R)\left(\lambda x . S(x)_{F(x)}\right)
$$

In (25), 'no' is just the well known English determiner, ' $R$ ' is its restrictor, ' $S$ ' is the predicate of its nuclear scope and ' $F$ ' is the predicate of a presupposition triggered by $S$ (or material within $S$ ). Note that the presuppositional material contains a bound variable. $^{11}$

\footnotetext{
${ }^{11}$ I do not set out the predictions of the two schools for quantified sentences in general, including ones with other determiners, since it is widely recognized these days that different determiners give rise to different behaviour when it comes to the presuppositions triggered in their scope (Cooper 1983; Chemla 2009; Geurts and van Tiel 2016).
} 
The first school is composed of people whose theories predict, and whose judgements and experimental investigations appear to confirm, that there are universal presuppositions here (Cooper 1983; Heim 1983; Chemla 2009; Schlenker 2008, 2009; Romoli 2015). ${ }^{12}$ A universal presupposition, in this context, is one whose content is the following, where the ' $R$ ' and ' $F$ ' are meant to recall their use in (25).

(26) $\forall x(R x \supset F x)$

For example, (27) includes the factive predicate 'knows', which in general introduces a presupposition to the effect that the proposition expressed by the subordinate clause following it is true. Here, however, the following clause includes a variable bound from outside it, which means that it does not express a proposition in isolation. What to do? The frameworks under discussion would analyse (27) as (28). This means that it is predicted to have the presupposition in (29):

(27) No student knows that he is lucky.

(28) $\llbracket$ no $\rrbracket(\llbracket$ student $\rrbracket)\left(\lambda x . x\right.$ knows that $x$ is lucky $\left._{x \text { is lucky }}\right)$

(29) Every student is lucky.

In the case of example (7), then, we have the analysis in (30) and the predicted presupposition in (31).

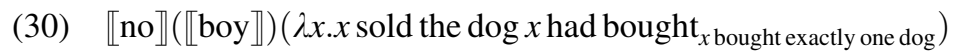

(31) Every boy bought exactly one dog.

Let us call the position that there are universal presuppositions here 'the universal theory'.

The second school is composed of people whose theories predict, and whose judgements and experimental investigations appear to confirm, that there are existential presuppositions here (van der Sandt 1992; Geurts and van der Sandt 2011; Beaver 2001; Geurts and van Tiel 2016). That is to say that they predict and find presuppositions of the form in (32). In the case of (7) (again given the analysis in (28)), the predicted presupposition would be (33).

(32) $\exists x(R x \& F x)$

(33) Some boy bought exactly one dog

We can call the position that there are existential presuppositions here 'the existential theory'.

The dispute between the universal theory and the existential theory is a complex one and I will not attempt to resolve it in this article. Fortunately, I do not need to. For present purposes, it suffices to point out that both theories predict the facts about (7) (repeated here for convenience as (34)) that we noted in (8) (repeated here as (35)):

${ }^{12}$ Rothschild (2011: 34-5) endorses the relevant judgements and takes pains to point out that his theory is at least compatible with them, even if the core of it does not predict them, so we should probably include him here too. 
(34) No boy sold the dog he had bought.

(35) a. Fact A: (34) is not true in a scenario in which no boy bought any dog.

b. Fact B: (34) is not true in a scenario in which all the boys bought two or more dogs.

The universal theory, to take that first, predicts that the presupposition of (34) will be (31). Let us further suppose, as is plausible, that speakers spontaneously assume, in processing (34), that there are some boys. Then, given that presupposition failure produces judgements of 'false' or 'neither true nor false', depending on the speaker and on various other circumstances whose exact nature is still under discussion (Strawson 1954, 1964; Lasersohn 1993; von Fintel 2004; Yablo 2006, 2009; Schoubye 2009; Elbourne 2013; Felka 2015), we immediately predict Fact A and Fact B: the presupposition that every boy bought exactly one dog is incompatible both with no boy buying any $\operatorname{dog}$ (Fact A) and with every boy buying two or more dogs; there will be presupposition failure, then, which will lead to the sentence not being judged true in the scenarios in question.

We can be even briefer in laying out the predictions of the existential theory. It predicts that (34) presupposes that some boy bought exactly one dog. This is, once more, incompatible with no boy buying any dog and with every boy buying two or more dogs. So we predict the facts in (35).

I conclude, then, that presuppositional theories of definite descriptions straightforwardly predict the data surveyed in this paper.

\section{Conclusion}

We can conclude that the new data involving negative existential quantifiers pose a significant problem for the Russellian theory. But presuppositional theories easily explain them. So presuppositional theories are empirically superior to the Russellian theory in this respect. This result should be seen in the context of previous arguments for presuppositional theories over the Russellian theory (Heim 1991; von Fintel 2004; Elbourne 2005, 2010, 2013; Rothschild 2007; Abbott 2008; Hawthorne and Manley 2012; Schoubye 2013).

In my opinion, the debate about the semantics of definite descriptions now comes down to a debate between Fregean and quantificational presuppositional theories. ${ }^{13}$ But resolving that debate is beyond the scope of this article.

\footnotetext{
13 I have sometimes, in conversation and in seminars, come across people who object to presuppositional theories of definite descriptions because they take such theories to involve abandoning bivalence for natural language. Now I see nothing wrong with abandoning bivalence myself; and opponents of presuppositions in definite descriptions would presumably also have to argue that the presuppositions arising from the many other presupposition triggers (factive verbs, aspectual verbs, clefts...) also do not force one to abandon bivalence. But such theorists might like to pursue the possibility, argued for by Schlenker (2008), that presupposition failure does not involve a lack of truth value or a third truth value but a mere pragmatic infelicity, a violation of a Gricean maxim. When one takes account of recent theories of presupposition, then, it is not certain that adhering to a presuppositional theory of definite descriptions does involve abandoning bivalence.
} 
Acknowledgements I presented a version of this paper at the Philosophical Society in Oxford University in November 2016. I am grateful to everyone who attended and especially, for their comments and questions, to James Kirkpatrick, Ofra Magidor, and Peter Millican. I am particularly grateful to an anonymous reviewer for Philosophical Studies for detailed and thoughtful comments that significantly improved the paper.

Open Access This article is distributed under the terms of the Creative Commons Attribution 4.0 International License (http://creativecommons.org/licenses/by/4.0/), which permits unrestricted use, distribution, and reproduction in any medium, provided you give appropriate credit to the original author(s) and the source, provide a link to the Creative Commons license, and indicate if changes were made.

\section{References}

Abbott, B. (2008). Issues in the semantics and pragmatics of definite descriptions in English. In J. K. Gundel \& N. Hedberg (Eds.), Reference: Interdisciplinary perspectives (pp. 61-72). Oxford: Oxford University Press.

Abrusán, M., \& Szendröi, K. (2013). Experimenting with the King of France: Topics, verifiability and definite descriptions. Semantics and Pragmatics, 6(10), 1-43.

Bach, K. (2007a). The main bone of contention. European Journal of Analytic Philosophy, 3(2), 55-57.

Bach, K. (2007b). Referentially used descriptions: A reply to Devitt. European Journal of Analytic Philosophy, 3(2), 33-48.

Beaver, D. (2001). Presupposition and assertion in dynamic semantics. Stanford: CSLI Publications.

Chemla, E. (2009). Presuppositions of quantified sentences: Experimental data. Natural Language Semantics, 17, 299-340.

Christophersen, P. (1939). The articles: A study of their theory and use in English. Copenhagen: Munksgaard.

Cooper, R. (1983). Quantification and syntactic theory. Dordrecht: Reidel.

Elbourne, P. (2005). Situations and individuals. Cambridge, MA: MIT Press.

Elbourne, P. (2010). The existence entailments of definite descriptions. Linguistics and Philosophy, 33(1), $1-10$.

Elbourne, P. (2013). Definite descriptions. Oxford: Oxford University Press.

Felka, K. (2015). On the presuppositions of number sentences. Synthese, 192, 1393-1412.

Frege, G. (1892). Über Sinn und Bedeutung. Zeitschrift für Philosophie und Philosophische Kritik, 100, 25-50.

Geurts, B., \& van der Sandt, R. (2011). Domain restriction. In P. Bosch \& R. van der Sandt (Eds.), Focus: Linguistic, cognitive, and computational perspectives (pp. 268-292). Cambridge: Cambridge University Press.

Geurts, B., \& van Tiel, B. (2016). When 'All the Five Circles' are four: New exercises in domain restriction. Topoi, 35, 109-122.

Green, K. (2007). Bertrand Russell, language and linguistic theory. London: Continuum.

Hawkins, J. (1978). Definiteness and indefiniteness: A study in reference and grammaticality prediction. London: Croom Helm.

Hawthorne, J., \& Manley, D. (2012). The reference book. Oxford: Oxford University Press.

Heim, I. (1982). The semantics of definite and indefinite noun phrases. Ph.D. thesis, University of Massachusetts, Amherst.

Heim, I. (1983). On the projection problem for presuppositions. In M. Barlow, D. Flickinger, \& M. Westcoat (Eds.), WCCFL 2: Second Annual West Coast Conference on Formal Linguistics (pp. 114-126). Stanford: Stanford University.

Heim, I. (1991). Artikel und Definitheit. In A. von Stechow \& D. Wunderlich (Eds.), Semantik. Ein internationales Handbuch der zeitgenössischen Forschung (pp. 487-535). Walter de Gruyter: Berlin.

Jandrić, A. (2014). 'The King of France is Bald' reconsidered: A case against Yablo. Philosophical Studies, 169(2), 173-181. 
Kaplan, D. (2005). Reading 'On Denoting' on its centenary. Mind, 114, 933-1003.

Karttunen, L., \& Peters, S. (1979). Conventional implicature. In C.-K. Oh \& D. Dinneen (Eds.), Syntax and semantics 11: Presupposition (pp. 1-56). New York: Academic Press.

Lasersohn, P. (1993). Existence presuppositions and background knowledge. Journal of Semantics, 10(2), 113-122.

Neale, S. (1990). Descriptions. Cambridge, MA: MIT Press.

Neale, S. (2004). This, that, and the other. In M. Reimer \& A. Bezuidenhout (Eds.), Descriptions and beyond (pp. 68-182). Oxford: Oxford University Press.

Neale, S. (2005). A century later. Mind, 114, 809-871.

Neale, S. (2007). Heavy hands, magic, and scene-reading traps. European Journal of Analytic Philosophy, $3(2), 77-132$.

Pupa, F. (2010). On the Russellian Reformation. Philosophical Studies, 147, 247-271.

Pupa, F. (2013). Embedded definite descriptions: A novel solution to a familiar problem. Pacific Philosophical Quarterly, 94, 290-314.

Roberts, C. (2003). Uniqueness in definite noun phrases. Linguistics and Philosophy, 26, 287-350.

Romoli, J. (2015). The presuppositions of soft triggers are obligatory scalar implicatures. Journal of Semantics, 32(2), 173-219.

Rothschild, D. (2007). Presuppositions and scope. Journal of Philosophy, 104(2), 71-106.

Rothschild, D. (2011). Explaining presupposition projection with dynamic semantics. Semantics and Pragmatics, 4(3), 1-43.

Russell, B. (1905). On denoting. Mind, 14, 479-493.

Russell, B. (1919). Introduction to mathematical philosophy. London: George Allen and Unwin.

Salmon, N. (2004). The good, the bad, and the ugly. In M. Reimer \& A. Bezuidenhout (Eds.), Descriptions and beyond (pp. 230-260). Oxford: Oxford University Press.

Schlenker, P. (2008). Be articulate: A pragmatic theory of presupposition projection. Theoretical Linguistics, 34(3), 157-212.

Schlenker, P. (2009). Local contexts. Semantics and Pragmatics, 2(3), 1-78.

Schoubye, A. (2009). Descriptions, truth value intuitions, and questions. Linguistics and Philosophy, 32(6), 583-617.

Schoubye, A. (2013). Ghosts, murderers, and the semantics of descriptions. Noûs, 47(3), 496-533.

Searle, J. (1969). Speech acts: An essay in the philosophy of language. Cambridge: Cambridge University Press.

Soames, S. (2014). The analytic tradition in philosophy. Vol. 1: The founding giants. Princeton: Princeton University Press.

Strawson, P. (1952). Introduction to logical theory. London: Methuen.

Strawson, P. (1954). A reply to Mr Sellars. Philosophical Review, 63, 216-231.

Strawson, P. (1964). Identifying reference and truth-values. Theoria, 30, 96-118.

van der Sandt, R. (1992). Presupposition projection as anaphora resolution. Journal of Semantics, 9 , 333-377.

von Fintel, K. (2004). Would you believe it? The King of France is back! (Presuppositions and truth-value intuitions). In M. Reimer \& A. Bezuidenhout (Eds.), Descriptions and beyond (pp. 315-341). Oxford: Oxford University Press.

Yablo, S. (2006). Non-catastrophic presupposition failure. In A. Byrne \& J. J. Thomson (Eds.), Content and modality: Themes from the philosophy of Robert Stalnaker (pp. 164-190). Oxford: Oxford University Press.

Yablo, S. (2009). Must existence-questions have answers? In D. Chalmers, D. Manley, \& R. Wasserman (Eds.), Metametaphysics: New essays on the foundations of ontology (pp. 507-525). Oxford: Oxford University Press. 